\title{
Awareness Of HIV/Aids- For Future Generation
}

\author{
Amsa $\mathrm{P}^{1^{*}}$, Vinoth $\mathrm{K}^{2}$, Thirumaran $\mathrm{J}^{3}$, Hamidhunniza ${ }^{4}$ \\ ${ }^{1}$ Professor, Department of Pharmaceutics, Nandha College of Pharmacy, Erode, \\ Tamilnadu, Email: sushmiatn@gmail.com \\ ${ }^{2}$ Associate Professor, Department of Pharmaceutics, Nandha College of Pharmacy, \\ Erode, Tamilnadu, Email: vinoth@nandhapharmacy.org \\ ${ }^{3}$ Assistant Professor, Department of Pharmaceutics, Nandha College of Pharmacy, \\ Erode, Tamilnadu, Email:thiru.mrn@gmail.com \\ ${ }^{4}$ Professor, Department of Obstetrics and Gynecological Nursing, Nandha College of \\ Nursing, Erode, Tamilnadu, Email: Hamidaansar07@gmail.com \\ ${ }^{*}$ Corresponding Author
}

\begin{abstract}
The goal of this study was to envision if introducing additional HIV/AIDS instructional interventions can lead to fewer HIV/AIDS cases among young. Despite the very fact that new HIV infections among youngsters (15-24 years) have attenuated by forty proportion within the last decade, the world continues to be falling in need of the objectives established for young people. Success has been inconsistent, with sharp decreases in new HIV infections among young people in certain countries, notably in jap and Southern continent and Asia, however modest progress in alternative countries in lowering HIV incidence among young vital groups. During this paper necessary awareness and data is given for teens to create HIV/AIDS free future generation.
\end{abstract}

Keywords: youth, future generation, HIV, Awareness.

\section{Introduction}

In terms of recent infections and potential to stop HIV/AIDS transmission, teenagers are at the geographic point of the worldwide HIV/AIDS pandemic. though the severity of the pandemic varies by region, young people are the foremost powerful push for change. If they will be reached with the proper treatments, they will change. If effective preventative interventions are adopted early, young people are much more possible to adopt and retain safe practices, reducing the incidence of this disease. HIV/AIDS is joined to variety of problems that jeopardize people' health and their rights, as well as difference and discrimination, poverty, social upheaval and migration, exploitation and abuse. dynamic these structural and discourse components are going to be essential to making sure long-run HIV prevention. However, there has been growing expertise with a spread of shorter-term treatments geared toward encouraging individuals to avoid or lower the chance related to the behaviors that underpin HIV transmission. The goal of this study was to demonstrate however teaching future generations might cause fewer HIV/AIDS cases among teenagers. This analysis is vital for the audience of 14-18 year olds, who are the foremost liable to HIV infection. Minority children are additional in danger for HIV once risk behaviors are equal. Future study associate degreed resources should specialise in the underlying social problems that contribute to those gaps, further as policies and programs that encourage structural and socioeconomic reforms. currently that there are world objectives and targets, as well as an increasing range of treatments that will facilitate reach them, it' essential to synthesis the proof base for these interventions in ways in which help policymakers and programed planners create decisions. The outcomes of the analysis must assist them in crucial a way to best distribute resources in varied epidemic contexts and for various teams of young people. there's now wide accord concerning the most settings through that teenagers is reached with preventive interventions; these embody schools, health services, and also the mass media and thru communities and stretch programs targeting the young people who are most in danger of HIV.

\section{HIV in youth}

Depending at the kind of pandemic that exists withinside the country in which they reside, younger human beings are uncovered to HIV in loads of ways. The repute of younger human beings residing in international locations in which there may be a lowdegree epidemic, a focused epidemic, or a vast epidemic is tested on this section. HIV may also had been detected for decades in low-degree outbreaks, however incidence has in no way constantly exceeded $5 \%$ in any demographic. Sharing needles and syringes with an HIV-advantageous character is the simplest manner to unfold the virus. As a result, individuals who percentage injecting gadget run a good sized 
hazard of acquiring HIV. Drug utilization typically develops during adolescence, in keeping with statistics from some of international locations in Eastern Europe and Asia (14). According to a observe of research, as a minimum $1 / 2$ of of injectable drug customers in Russia are 25 years vintage or younger, and that they inject pills for a median of 3-four years. Being a younger injectable drug consumer will increase your possibilities of having HIV. Young human beings will function a crucial hyperlink among numerous demographic groupings. Young injecting drug customers, for example, are much more likely to be sexually active, setting their companions prone to HIV similarly to the dangers given through the excessive charges of sexually transmitted illnesses . The reality that many ladies are younger, regularly extensively younger, than their male sexual companions is one of the sociological motives why younger ladies have extra HIV incidence and prevalence than younger males. HIV incidence is extensively extra amongst younger ladies who stated having intercourse with older guys than amongst individuals who completely had sex with companions their very own age, in keeping with research from many nations. The provision of primary expertise on the way to guard themselves and their companions from contracting the virus is a crucial, however insufficient, foundation for any preventive marketing campaign centered at younger human beings. Schools are essential in offering HIV/AIDS schooling to younger human beings due to the fact they now no longer most effective have the capacity to attain a large quantity of pupils, however they may be additionally noticeably open to new information. As a result, faculties are a well-hooked up supply of touch for HIV/AIDS schooling for younger human beings. At the identical time, in many nations in which a big percent of the populace has been identified with HIV or AIDS, elevated funding in schooling is essential for offering powerful HIV prevention for younger human beings. HIV/AIDS interventions on the network degree have a essential effect withinside the epidemic's unfold. The awareness is an increasing number of on converting policies, social structures, social norms, and cultural practises that surround character hazard behaviours through attractive with communities. Many of those techniques emphasise the need of the use of participatory strategies to comprise and empower human beings.

\section{Education}

Young people will get HIV/AIDS information and lifeskills education in a very kind of methods, together with peer education or counselling, community activities that embody parents, the media, and school-based education programmes. These treatments are ofttimes scattered throughout multiple organisations and community groups, creating it troublesome to trace and measure their impact consistently. Schools, on the opposite hand, are a very important location for disseminative information and teaching adolescents the life skills they have to avoid HIV/AIDS. Any national preventive programme should include the availability of youthfriendly health services. the foremost important services for HIV prevention. the supply of services continues to be minimal . youngsters in most nations have less access to physiological state care than older individuals, and this can be very true for adolescents . the types of initiatives that are employed in developing nations to boost young people' access to health services, furthermore as their efficacy. The demand for counsel and testing can rise as antiretroviral medication becomes more wide offered. Testing services should be available to young people so as for them to use them. several factors influence access, however knowing wherever testing and counselling are available is certainly the foremost vital initial step. Information, education, and repair access ought to all contribute to the event of life skills that $\{$ may\} alter a young person' risk to HIV infection be reduced. However, there's no internationally comparable standardised approach for crucial whether or not youngsters have developed adequate accommodative and positive behaviours to cope well with the pressures of everyday life. as a result of they lack the abilities to barter abstinence, limit the amount of partners they have, or use condoms, young people may participate in unsafe sex despite having a high degree of understanding regarding preventive techniques. Risky behaviour should be reduced if young people have smart life skills.

\section{Social conditions}

In communities, there are norms and values that improve or lower the danger of HIV infection. oldsters and completely different own circle of relatives people play a essential position in instructing their children with records and competencies. However, in many cultures and civilizations, sincere dialogue some physiological property stays a struggle. Boys and girls may be humiliated to talk approximately intercourse concerns, and pop and mum can be hesitant or uncomfortable speakme approximately intercourse, all of that may end in younger humans having lean records and competencies concerning prevention. Boys and ladies can be reluctant to upset intercourse concerns, and dad and mum may be hesitant or uncomfortable discussing intercourse, all of that may end in younger humans having lean preventative understanding and abilities.

\section{Conclusion}

It ought to be a priority to teach children regarding HIV before they begin collaborating in activities that place them in danger of infection. though it's the responsibility of fogeys to determine values and provides moral\} and ethical basis for his or her children, faculties play an important role in giving current and proper knowledge concerning biological 
and scientific parts of health education. It' essential to supply a foundation of health education that emphasises the benefits of abstinence and suspending or proscribing sexual interactment, whereas conjointly guaranteeing that children who prefer to engage in gender have the knowledge they need to shield themselves. The stigma related to HIV/AIDS is decreasing as a lot of preventative intervention programmes are provided to young people. even supposing today' children have engaged during a form of bad sexual practises, several fail to hunt treatment for his or her health problems. The stigma and restrictions associated with this sickness are one amongst society' most serious issues.

\section{References}

1. UNICEF, UNAIDS, WHO. Young people and HIV/AIDS opportunity in crisis. New York, UNICEF, 2002.

2. National Research Council, Institute of Medicine. Growing up global: the changing transitions to adulthood in developing countries. Washington, DC, National Academy Press, 2005.

3. Dittus P.Miller, Why Parents Matter? : The conceptual basis for a community based HIV Prevention program for the parents of African American youth. Journal of Child and Family Studies 2004; 13(1):5-20.

4. El Bcheraoui, Charbel ; Sutton, Madeline Y. ; Hardnett, Felicia P,(2011) Patterns of condom use among students at historically Black colleges and universities: Implications for HIV prevention efforts among collegeage young adults. AIDS Care: Psychological and Sociomedical Aspects of AIDS/HIV, 15(2).

5. Hall, Henry, Rhodes, P., (2008) Estimation of HIV incidence in the United States. JAMA ; 300:520-429 .

6. Karofsky, PS (2000) Relationship between adolescent parental communication and initiation of first intercourse by adolescents. Journal of Adolescent Health 2000: 28; 41-45

7. Outlaw A, Naar-King S, Janisse $\mathrm{H}$, et al. Predictors of condom use in a multisite study of highrisk youth living with HIV. AIDS Edu. Prev. 2010;22:1-14.

8. Peersman, G., Levy J. (2008). Focus and Effectiveness of HIV-prevention efforts for young people. AIDS 12(Suppl. A): S191-S196

9. Prejean J, Song R, Hernandez A, et al. (2011) Estimated HIV incidence in the United States, 20062009; 6:e17502

10. Poobalan AS, Pitchforth E, Imamura M, Tucker JS, Philip K, Spratt J, Mandava L, van Teijlingen E. (2009) Characteristics of effective interventions in improving young people's sexual health: a review of reviews. Sex Education; 9(3):319-336 